\title{
KETAMINE AND DEXMEDETOMIDINE FOR DAY CARE ANAESTHESIA IN PAEDIATRIC SURGERY
}

Ravi Nagaprasad Yerramilli1, Muralidhar Aavula²

${ }_{1}^{1}$ Assistant Professor, Department of Anaesthesiology, Osmania Medical College.

${ }^{2}$ Assistant Professor, Department of Anaesthesiology, Osmania Medical College.

\section{ABSTRACT}

\section{BACKGROUND}

Ketamine is one of the commonly used inducing agent for short surgical procedures particularly in paediatric patients. But, its utility has been restricted because of its unwanted sympathomimetic activity even though it has an excellent analgesic property with minimal respiratory depression. Added to this, it is also associated with undesirable postoperative delirium. In the past, several drugs like Midazolam, Propofol were added to ameliorate the side effects of Ketamine. A Combination of Dexmedetomidine, a shortacting highly selective $\alpha_{2}$ negates the unwanted sympathomimetic effects of Ketamine. It also reduces the postoperative hallucination and its antiemetic and antisialagogues properties are beneficial. Several studies have been done to evaluate Ketamine and Dexmedetomidine as a sedative in diagnostic and invasive procedures in children. We have studied its efficacy in short surgical procedures in paediatric cases.

\section{METHODS}

The study has been done to evaluate the efficacy of dexmedetomidine-Ketamine combination in day care surgeries in paediatric patients.

\section{RESULTS}

Ketamine and Dexmedetomidine combination anaesthesia produced stable perioperative cardiovascular parameters with good postoperative sedation and smooth recovery. There were no undesirable incidences like respiratory depression or hypoventilation and PONV during postoperative period.

\section{CONCLUSION}

Ketamine-Dexmedetomidine combination provides good haemodynamic stability during intraoperative period. Dexmedetomidine has addition property of sedation, antiemesis and analgesia, which makes better choice of drug for combining with Ketamine.

\section{KEYWORDS}

Ketamine, Dexmedetomidine, Selective Alpha-2 Agonist, Day Care Surgeries.

HOW TO CITE THIS ARTICLE: Yerramilli RN, Aavula M. Ketamine and dexmedetomidine for day care anaesthesia in paediatric surgery. J. Evolution Med. Dent. Sci. 2016;5(72):5257-5260, DOI: 10.14260/jemds/2016/1191

\section{INTRODUCTION}

In recent years, there has been an increased amount of day care surgeries in paediatric age group. ${ }^{1}$ Children make excellent candidates for day care surgeries as they are usually healthy, free from systemic diseases and they typically require minor and short surgical procedures. ${ }^{1}$ Thus, anaesthesiologists face more frequently the task of managing day care anaesthesia in children.

Induction of anaesthesia either by I.V. or inhalation is suitable in paediatric day care surgeries. The choice depends on the needs of individual child with main goal being smooth atraumatic induction. IV induction has become increasingly popular since the introduction of local anaesthetic skin preparations. ${ }^{1}$ There is some evidence that IV induction is less psychologically disturbing than inhalation methods. ${ }^{1}$ In ambulatory practice, Total Intravenous Anaesthesia (TIVA) provides advantages for all short surgical procedures. TIVA is

Financial or Other, Competing Interest: None.

Submission 29-07-2016, Peer Review 22-08-2016,

Acceptance 29-08-2016, Published 07-09-2016.

Corresponding Author:

Dr. Ravi Nagaprasad Yerramilli,

\#B/4, Madhura Nagar,

S. R. Nagar (P.O.),

Hyderabad-500038, Telangana.

E-mail: yerramilli.rnp@gmail.com

DOI: $10.14260 /$ jemds/2016/1191 found to have advantages of shorter recovery and no agitation or other behavioural disorder even after prolonged infusion. ${ }^{2}$ Commonly used IV agents for TIVA in day care surgeries are Propofol, Fentanyl, Ketamine, Midazolam and Dexmedetomidine. They produce rapid induction and recovery of anaesthesia.

Ketamine is a phencyclidine derivative. It provides excellent amnesia and analgesia, preserves muscle tone with maintaining air reflexes and spontaneous respiration. But, its drawbacks are frightening emergent reactions, sympathomimetic effects, vomiting and excessive salivation. Ketamine is often combined with midazolam or propofol to alleviate these adverse effects.

Dexmedetomidine is a highly selective $\alpha_{2}$-agonist. It has sedative and anxiolytic properties similar to benzodiazepines. It also produces perioperative analgesia and reduces the narcotic dose requirement. Dexmedetomidine has antiemetic properties and does not possess respiratory depression like benzodiazepines. However, co-administration of dexmedetomidine with other anaesthetic agents, sedatives, hypnotics or opioids is likely to cause additive effects. It attenuates stress-induced sympathoadrenal responses protecting the patients from noxious sympathetic stimulation and haemodynamic changes. ${ }^{3}$ A prospective observational study to evaluate the efficacy of Ketamine with Dexmedetomidine combination as an anaesthetic in paediatric day care surgeries was done. 


\section{AIM OF THE STUDY}

The purpose of the study is to evaluate the haemodynamic stability and recovery profile using KetamineDexmedetomidine combination in day care surgeries in paediatric age group.

\section{MATERIAL AND METHODS}

The study was conducted in Niloufer Hospital from April 2015 to June 2015. Day Care surgeries with the average duration of 40 mins. were taken under study. All the cases which are maintained by spontaneous mask ventilation were taken for study. The study cases had fasting period of $6 \mathrm{hrs}$. for solid food and $4 \mathrm{hrs}$. for clear fluids. All study cases were in the age group between 2 yrs. to 12 yrs. and are ASA GR I. Children with anaemia, CHD and any other associated medical abnormalities were excluded.

All the study cases were premedicated with I.V. atropine $10 \mathrm{mcg} / \mathrm{kg}$ body weight. Dexmedetomidine $1 \mathrm{mcg} / \mathrm{kg}$ body weight in $50 \mathrm{~mL}$ of Normal Saline was started and infused for 30 mins. Induction was done with Inj. Ketamine $2 \mathrm{mg} / \mathrm{kg}$ body weight I.V. Patients were maintained with $\mathrm{O}_{2}+\mathrm{N}_{2} \mathrm{O}$ on spontaneous ventilation by mask. Intraoperatively, PR/BP, SPO2 was monitored. A regional block either Penile block/Inguinal nerve block was given to all cases wherever indicated. Postoperative recovery is monitored by Aldrete score, Sedation score (modified Ramsay scale) and Wong Baker Pain Rating Score along with cardiovascular monitoring.

\section{ALDRETE SCORE}

Activity: Able to move voluntarily or on command

- Four extremities 2

- 2 extremities

- $\quad$ No extremities

\section{Respiration}

- Able to breathe deeply and cough freely 2

- Dyspnoea, shallow and limited breathing

- Apnoea

1

\section{Circulation}

- Systolic BP $<20 \mathrm{mmHg}$ of preoperative 2

- Systolic BP 20-50 mmHg of preoperative 1

- Systolic BP + or - $20 \mathrm{mmHg}$ of preoperative

\section{Consciousness}

- Fully Awake 2

- Arousable on calling 1

- Deeply sedated

\section{Oxygen Saturation}

- $\quad$ Saturation $>92 \%$

- $\quad$ Needs $\mathrm{O}_{2}$ for maintaining $>90 \%$ 1

- $\mathrm{O}_{2}$ saturation $<90 \%$ with $\mathrm{O}_{2}$ supplementation 0

\section{Sedation Score (Modified Ramsay Scale)}

1. Fully Awake and Anxious.

2. Calm adequate cooperation.

3. Arousable to verbal comments.

4. Arousable to mild stimulation/vigorous reaction to painful stimulation.

5. Slow/incomplete reaction to painful stimulation.

6. No reaction to painful stimulation.
( 5 and 6 were considered as satisfactory sedation.)

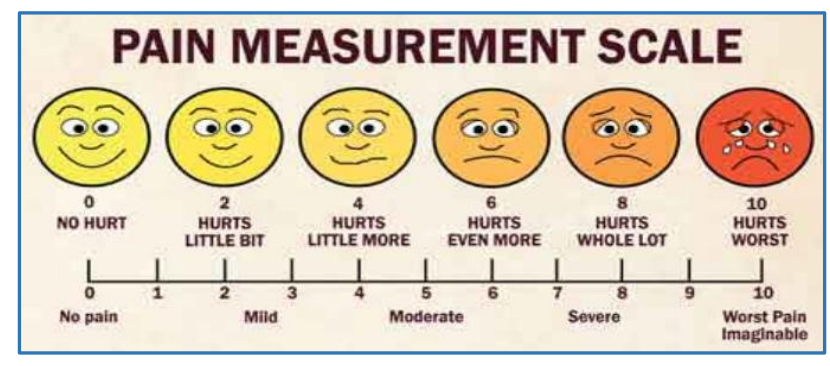

Wong-Baker Pain Rating Score

Postoperative PR, BP, SpO2, Sedation score, Aldrete scores and Pain score of each patients were noted for $2 \mathrm{hrs}$. All the patients were kept in PICU till they attain Aldrete score of 810. All patients were looked for PONV. Ondansetron $0.2 \mathrm{mg} / \mathrm{kg}$ is given IV if child has PONV. All the patients were given 20 $\mathrm{mg} / \mathrm{kg}$ of paracetamol suppository at the end of surgery. IV Fentanyl $0.5 \mathrm{mcg} / \mathrm{kg}$ bolus was considered as rescue analgesic in case if it is required. Bradycardia if occurred treated with a bolus dose of atropine $0.01 \mathrm{mg} / \mathrm{kg}$. If Hypotension ( $>20 \mathrm{mmHg}$ of preoperative level) is detected IV fluid $1 / 2$ DNS $10 \mathrm{~mL} / \mathrm{kg}$ was given bolus.

\section{OBSERVATION}

\begin{tabular}{|c|c|}
\hline No. of Cases & $\mathbf{2 0}$ \\
\hline No. Boys & 8 \\
\hline No. Girls & 12 \\
\hline Mean Age & $7.45 \mathrm{yrs}$. \\
\hline Mean Weight & $19.25 \mathrm{Kg}$. \\
\hline \multicolumn{2}{|c|}{ Table 1: Demography } \\
\hline
\end{tabular}

\begin{tabular}{|c|c|}
\hline Name of the Surgery & No. Surgery \\
\hline Anal Dilatation & 1 \\
\hline Circumcision & 7 \\
\hline Herniotomy & 3 \\
\hline Cystoscopy & 5 \\
\hline DJ Stent Removal & 2 \\
\hline Collagen Graft Dressing & 1 \\
\hline Suturing & 1 \\
\hline \multicolumn{2}{|c|}{ Table 2: Surgical Profile } \\
\hline
\end{tabular}

\begin{tabular}{|c|c|c|}
\hline Period & $\begin{array}{c}\text { Mean } \\
\text { PR/mins. }\end{array}$ & Mean BP mmHg \\
\hline Preoperative & 112 & 52.05 \\
\hline Intraoperative & & 51.9 \\
\hline 5 mins. & 108.1 & 51 \\
15 mins. & 96.75 & 51 \\
30 mins. & 102.45 & 51 \\
\hline Postoperative & & 52.5 \\
\hline 15 mins. & 100.4 & 55 \\
30 mins. & 108.1 & 52.5 \\
1 hr. & 108.3 & 110.1 \\
2 hrs. & \multicolumn{2}{|c|}{ Table 3: Haemodynamic Profile } \\
\hline \multicolumn{2}{|r}{} \\
\hline
\end{tabular}

\begin{tabular}{|c|c|c|c|c|}
\hline & $\begin{array}{c}\mathbf{1 5} \\
\text { mins. }\end{array}$ & $\begin{array}{c}\mathbf{3 0} \\
\text { mins. }\end{array}$ & $\mathbf{1}$ hr. & $\mathbf{2}$ hrs. \\
\hline Aldrete Score & 6 & 6 & 8 & 8 \\
\hline Sedation Score & 6 & 6 & 5 & 2 \\
\hline Pain Score & 0 & 2 & 2 & 4 \\
\hline \multicolumn{4}{|c|}{ Table 4: Recovery Profile } \\
\hline
\end{tabular}


One case had bradycardia with PR of $48 /$ mins. during intraoperative period, which was treated with $0.1 \mathrm{mg} / \mathrm{kg}$ of atropine I.V. bolus.

Postoperative sedation score during first 30 mins. in all cases was 6 [no reaction to painful stimulus] and at 120 mins. of postoperative period, sedation scores came to 2 [calm adequate cooperative].

Postoperative pain scores were 0 in first 30 mins. to all cases and were 2 after $2 \mathrm{hrs}$. [H].

\section{RESULTS}

The Mean PR and BP were found to be stable during the perioperative period. Only one case had bradycardia during intraoperative period, which was corrected with a bolus dose of IV Atropine.

Recovery scores showed patient had Aldrete score of 8 after 120 mins. All cases had sedation score of 6 for 2 hrs., which is advantageous to the paediatric age group. All patients had satisfactory analgesia during postoperative period.

None of them required any bolus rescue doses of Fentanyl during postoperative period. None of the cases had postoperative agitation.

None of the patients had PONV during perioperative period.

\section{DISCUSSION}

Ahmad Ramzi Sahban, Sahar Kamal et al $^{4}$ has compared Dexmedetomidine-Ketamine with Propofol-Ketamine combination for invasive procedures in oncology patients. They found recovery-related agitation was more common in Ketamine-Propofol combination whereas DexmedetomidineKetamine combination resulted smooth recovery pattern. They concluded that Dexmedetomidine and Ketamine combination provided stable cardiovascular parameters. Our study also showed Dexmedetomidine and Ketamine combination provided stable cardiovascular parameters and smooth recovery. Recovery scores and Pain scores are comparable to their studies. Only 1 case in our study had bradycardia, which was treated successfully with a bolus dose of injection Atropine.

Tarek Tammam ${ }^{5}$ in a comparative study of efficacy of dexmedetomidine-ketamine combination for MRI sedation. He found better sedation and better cardiovascular stability when compared to dexmedetomidine alone. In our study, we found satisfactory sedation and pain scores in $2 \mathrm{hrs}$. of postoperative period.

All the studies done were for invasive procedure and diagnostic procedures. Our study is to evaluate haemodynamic stability of Dexmedetomidine-Ketamine combination in paediatric day care surgeries.

Koruk et al 6 prospectively compared sedation using Dexmedetomidine and Ketamine to a regimen using midazolam and ketamine during extracorporeal shock wave lithotripsy in a Cohort of 50 paediatric patients who ranged in the age 2-15 yrs. They found the recovery sedation scores were similar in both the regimen. Incidence of nausea and vomiting was significantly lower in dexmedetomidineketamine combination. In our study, none of the patients had nausea and vomiting.

Joseph D Tobias7 in an article "Dexmedetomidine and Ketamine" in Paediatric Critical Care Medicine reported the potential utility of the combination of ketamine and dexmedetomidine for procedural sedation even in patients with compromised respiratory or cardiac function. When compared with other agents used for procedural sedation, these two agents have limited effects on respiratory function. Bloor, Ward et $\mathrm{al}^{8}$ used respiratory inductance plethysmography in their study to evaluate respiratory depression while using dexmedetomidine or propofol with ketamine. They found respiratory depression with these combination was rare and it was due to obstructive cause and not central cause. In our study, we did not detect any hypoventilation or desaturation in our patients.

Rakhee $\mathrm{Goyal}^{9}$ in an article in correspondence column in Paediatric Anaesthesia reported that KetamineDexmedetomidine (available as "Ketodex") is a useful and practical alternative to standard drugs used in TIVA. Adverse effects are less during perioperative period and recovery time is more with this combination when compared to other drugs like propofol and midazolam. In our study, all cases had sedation scores were $6 / 5$ for $1 \mathrm{hr}$. Sedation score of 2 (Arousable Sedation) after 2 hrs. of postoperative period.

Goyal R, Shivinder Singh et al used DexmedetomidineKetamine combination in non-cardiac surgeries in patients with CHD. They found patients were haemodynamically stable with smooth recovery with this combination. ${ }^{10}$

\section{CONCLUSION}

This prospective observational study reveals that Anaesthesia with dexmedetomidine-Ketamine combination produces stable haemodynamic parameters during perioperative period. These two drugs make a perfect combination by one ameliorating the side effects of other drug. A smooth postoperative recovery without respiratory depression, nausea, vomiting is an added advantage. All the other studies on this combination, which were done on paediatric age group had similar reports.

\section{REFERENCES}

1. Brennan LJ. Modern day case anesthesia for children. Br J Anaesth 1999;83(1):91-103.

2. Harsoor SS. Changing concepts in anesthesia for day care surgery. Indian J Anaesthesia 2010;54(6):485-8.

3. Abdalla MW, El Shal SM, El Sombaty AL, et al. Propofol dexmedetomidine verses propofol ketamine for anesthesia of endoscopic retrograde cholangiopancreatography (ERCP). A randomized comparative study. Egyptian Journal of Anaesthesia 2015;31(2):97-105.

4. Shaaban AR, Kamal S, Okasha MM. Comparison of dexmedetomidine versus propofol for maintenance of anesthesia during invasive procedures in pediatric oncology patients: a controlled randomized double-blind study. Ains Shams J Anaesthesiology 2014;7(2):163-9.

5. Tammam TF. Comparison of the efficacy of dexmedetomidine, ketamine, and a mixture of both for pediatric MRI sedation. Egyptian Journal of Anaesthesia 2013;29(3):241-6.

6. Koruk S, Mizrak A, Gul R, et al. Dexmedetomidineketamine and midazolam-ketamine combinations for sedation in pediatric patients undergoing extracorporeal shock wave lithotripsy: a randomized prospective study. J Anesth 2010;24(6):858-63. 
7. Tobias JD. Dexmedetomidine and ketamine: an effective alternative for procedural sedation? Pediatr Crit Care Med 2012;13(4):423-7.

8. Bloor BC, Ward DS, Belleville JP, et al. Effects of intravenous dexmedetomidine in humans. II. Hemodynamic changes. Anesthesiology 1992;77(6): 1134-42.
9. Goyal R. Total intravenous anesthesia with dexmeditomidine and ketamine in children. Pediatric Anesthesia 2015;25(7):753-7.

10. Goyal R, Singh S, Bangi A, et al. Case series: dexmedetomidine and ketamine for anesthesia in patients with uncorrected congenital cyanotic heart disease presenting for non-cardiac surgery. J Anaesthesiol Clin Pharmacol 2013;29(4):543-6. 